\title{
Atendimento Educacional Especializado: o caso de uma EMEF do Município de Cariacica-ES
}

\author{
Specialized Educational Assistance: the case of an EMEF in the Municipality \\ of Cariacica-ES \\ Asistencia especial para la asistencia sanitaria: el caso de un EMEF en la \\ Municipalidad de Cariacica-ES
}

Christine Avelar Borges Faria

Mestra pela Faculdade Vale do Cricaré, São Mateus, Espírito Santo, Brasil.

christine_avelar@hotmail.com

ORCID - https://orcid.org/0000-0003-4825-1047

Marcus Antonius da Costa Nunes

Professor doutor na Universidade Federal do Espírito Santo, Vitória, Espírito Santo, Brasil. marcaoantonius@gmail.com

ORCID - https://orcid.org/0000-0001-7971-8768

Isabel Matos Nunes

Professora doutora na Universidade Federal do Espírito Santo, Vitória, Espírito Santo, Brasil. nunesisabelmatos@yahoo.com

ORCID - https://orcid.org/0000-0001-9127-6384

Fabrício Aigner Pinto

Mestre pela Faculdade Brasileira UNIVIX, Serra, Espírito Santo, Brasil.

fabricioaigner@hotmail.com

ORCID - https://orcid.org/0000-0002-0175-8468

Recebido em 16 de outubro 2018

Aprovado em 2 de março 2019

Publicado em 10 de abril de 2020

\section{RESUMO}

O presente artigo trata de uma pesquisa exploratória que tem por objetivo verificar as especificidades do atendimento educacional especializado em uma Escola Municipal de Ensino Fundamental (EMEF) de Cariacica- ES, indicando o público alvo atendido, o trabalho das professoras da sala de recursos multifuncionais, bem como, as ressalvas das (os) professoras (os) regentes e colaboradoras neste âmbito de ensino, considerando as problemáticas enfrentadas pelos sujeitos que atuam nesta escola no contexto da educação especial. Este estudo faz uma reflexão sobre as Leis referentes à Educação Especial, esclarece as características da escola mencionada e conta com um questionário qualitativo com sete questões a fim de indagar os professores atuantes sobre a organização e os desafios inerentes ao atendimento educacional especializado na escola.

Palavras-chave: Educação Especial; Atendimento Educacional Especializado. 
http://dx.doi.org/10.5902/1984686X35228

\section{ABSTRACT}

This article deals with an exploratory research that aims to verify the specificities of specialized educational care in a Municipal Elementary School (EMEF) of Cariacica - ES, indicating the target audience, the work of teachers of the multifunctional resource room, as well as the caveats of the teachers who are the conductors and collaborators in this area of education, considering the problems faced by the subjects who work in this school in the context of special education. This study reflects on the Special Education Laws, clarifies the characteristics of the school mentioned and has a qualitative questionnaire with seven questions in order to ask the active teachers about the organization and the challenges inherent to the specialized educational attendance at the school.

Keywords: Special Education; Specialized Educational Service.

\section{RESUMEN}

El presente artículo trata de una investigación exploratoria que tiene por objetivo verificar las especificidades de la atención educativa especializada en una Escuela Municipal de Enseñanza Fundamental (EMEF) de Cariacica, indicando el público objetivo atendido, el trabajo de las profesoras de la sala de recursos multifuncionales, así como las salvedades de las (las) profesoras (as) regentes y colaboradoras en este ámbito de enseñanza, analizando las problemáticas enfrentadas por los sujetos que actúan en esta escuela en el contexto de la educación especial. Este estudio hace una reflexión sobre las Leyes referentes a la Educación Especial, aclara las características de la escuela mencionada y cuenta con un cuestionario cualitativo con siete cuestiones a fin de indagar a los profesores actuantes sobre la organización y los desafíos inherentes a la atención educativa especializada en la escuela.

Palabras clave: Educación Especial; Asistencia Educativa Especializada.

\section{Introdução}

A educação da pessoa com deficiência sempre esteve incorporada aos propósitos da qualificação da educação brasileira. Por este motivo, em diversas instâncias encontram-se apontamentos que buscam a legitimidade desta modalidade de ensino. Assim, a inclusão de alunos com deficiência nas escolas de ensino regular tornou-se uma forte bandeira presente na legislação internacional, e vem passando por diversas modificações em documentos e regimentos que norteiam a política da educação especial no Brasil. Tais modificações se refletem nos movimentos da gestão educacional dos municípios que organizam ações visando à efetivação dessa política.

Logo, a inclusão educacional para além da matrícula é discutida por estudantes e pesquisadores na ânsia de reconhecerem as principais assertivas que possibilitam a garantia da aprendizagem e da permanência dos sujeitos público alvo da educação especial $^{1}$, nas escolas comuns de ensino. Portanto, o presente artigo originou-se da vontade de contribuir com as demandas da educação especial de uma Escola de Ensino 
Fundamental do Município de Cariacica-ES, através da análise do seu cotidiano. Uma vez que este local também é campo de atuação docente de um dos pesquisadores deste trabalho.

Desta forma, pesquisou-se sobre os aspectos gerais da educação especial no município de Cariacica e as fundamentações teóricas e legais que trouxeram reflexões acerca desta temática, o que tornou possível um olhar atinado sobre a realidade do campo, diante da inquietação em aprofundar os estudos sobre as orientações legais, as ações municipais no que tange ao funcionamento do Atendimento Educacional Especializado (AEE), para alcançar insights sobre este campo de atuação.

O objetivo do estudo foi verificar as especificidades do Atendimento Educacional Especializado em uma Escola Municipal de Ensino Fundamental (EMEF) de Cariacica- ES, refletindo sobre o público alvo atendido, o trabalho das Professoras da Sala de Recursos Multifuncionais, bem como as ressalvas das (os) professoras (os) regentes e colaboradoras neste âmbito de ensino, podendo assim identificar possíveis desafios enfrentados pelos sujeitos desta escola no contexto da educação inclusiva.

O presente texto, modelado à tipologia dos autores Vergara (1988) e Gil (2002) tratase de uma pesquisa predominantemente exploratória, por buscar maior familiaridade com o tema, explorando o interior da área pesquisada, no entanto possui algumas características descritivas, pois visa descrever percepções e expectativas das (os) professoras (es) envolvidas (os) com o processo de inclusão escolar de alunos público alvo da Educação Especial.

A discussão tomará dois focos principais, o primeiro, os aspectos legais da constituição do atendimento educacional especializado (AEE) no Brasil, mencionando o contexto histórico, que resume brevemente a legislação responsável pela formação das salas de recursos multifuncionais e perpassa sobre as especificidades do público alvo da Educação Especial da unidade de ensino em questão. Para isso, foi realizada uma revisão de literatura, dialogando com o texto de Nunes e Borges (2017) por vossas experiências no contexto da Educação Especial no Espírito Santo e as referências de textos da Constituição da República (BRASIL, 1988), além de Leis e Decretos da Educação Brasileira (Brasil, 1996; 2008b; 2009).

No segundo momento, apresenta-se os dados empíricos sobre o funcionamento do AEE e as principais demandas vividas pelas (os) vinte professoras (es) de uma Escola 
http://dx.doi.org/10.5902/1984686X35228

Municipal de Ensino Fundamental (EMEF) de Cariacica-ES, que atuam pedagogicamente com trinta e dois alunos (as) público da Educação Especial.

O instrumento utilizado com as (os) professoras (es) foi um questionário qualitativo que indaga a percepção das (dos) mesmas (as) a respeito das práticas do seu cotidiano dando ênfase a modalidade da Educação Especial. A base para a elaboração do questionário incide em revelar os objetivos da pesquisa através das respostas das questões pertinentes (GIL, 2002).

A partir das informações coletadas neste estudo pôde-se ao final refletir possíveis ações que servirão para abrandar as lacunas existentes na organização do trabalho pedagógico para o público da Educação Especial, na garantia do direito à matricula, permanência e aprendizagem desses sujeitos, na escola comum, que apesar de correspondente, sempre estará em gradativa evolução.

\section{Contexto histórico a legislação da Educação Especial no Brasil}

A legislação que norteia a educação especial vem evoluindo e se modificando ao longo dos tempos. Assim, neste capítulo, apresentamos um panorama dos principais documentos que norteiam a modalidade da Educação Especial no Brasil, sobretudo àqueles que orientam o atendimento educacional especializado (AEE) na rede pública de ensino.

Vale lembrar que todas as pessoas têm direito a escolarização como regulamenta a Constituição Federal em seu artigo Art. 205 “A educação, direito de todos e dever do Estado e da família, será promovida e incentivada com a colaboração da sociedade, visando ao pleno desenvolvimento da pessoa [...]" (BRASIL, 1988, n.p.). No entanto, há a necessidade, com o passar dos anos, da elaboração de documentos norteadores que visam aprimorar a educação, e consequentemente a Educação Especial.

Com o advento de conferências internacionais, convenções e similares em âmbito internacional impulsionou avanços políticos, culturais e filosóficos. No entanto o ponto crucial para a elaboração das políticas de inclusão educacional foi a Conferência Mundial sobre Necessidades Educacionais Especiais: acesso e qualidade, promovida pelo governo espanhol, e a Organização das Nações Unidas para a Educação, a Ciência e a Cultura (Unesco), com a participação de delegados de 87 países, de onde derivou a conhecida Declaração de Salamanca (1994), utilizada como referência internacional basilar na área da educação especial (NUNES; BORGES, 2017). 
http://dx.doi.org/10.5902/1984686X35228

Os princípios de "Educação para todos", proclamados internacionalmente, também foram afirmados na Lei de Diretrizes e Bases da Educação Nacional (BRASIL, 1996, n.p.) e em diversos outros documentos nacionais que dispõem sobre a organização dos sistemas de ensino e a formação de professores visando à inclusão educacional (NUNES; BORGES, 2016).

É nesse contexto que se afirma a Lei de Diretrizes e Bases da Educação (BRASIL, 1996), tornando público no capítulo $V$, que a educação especial é uma modalidade de educação escolar oferecida preferencialmente na rede regular de ensino, para educandos com deficiência, transtornos globais do desenvolvimento e altas habilidades ou superdotação. Enfatizando que a educação especial inicia na educação infantil e estendese ao longo da vida do sujeito.

Atendendo o que rege a Lei de Diretrizes e Bases da Educação Nacional (BRASIL, 1996, n.p.), em 2008, após um debate nacional entre pesquisadores, políticos, instituições de defesa dos direitos da pessoa com deficiência, entre outros interessados, foi proposto um novo direcionamento para a Política de Educação Especial na perspectiva inclusiva. Esse documento traça o histórico do processo de inclusão escolar no Brasil e embasa as "políticas públicas promotoras de uma Educação de qualidade para todos os alunos".

Em seguida, com a aprovação do o Decreto № 6.571 (BRASIL, 2008b, n.p.), o qual dispôs sobre 0 atendimento educacional especializado (AEE) na educação básica e 0 definiu como "o conjunto de atividades, recursos de acessibilidade e pedagógicos organizados institucionalmente, prestado de forma complementar ou suplementar à formação dos alunos no ensino regular". O decreto obrigou a União a prestar apoio técnico e financeiro aos sistemas públicos de ensino no oferecimento da modalidade. Além disso, reforça que o AEE deve estar integrado ao projeto pedagógico da escola (BRASIL, 2008b, n.p.).

Posteriormente, em 2009 a resolução № 4 (BRASIL, 2009) focalizou em orientar a implementação do atendimento educacional especializado (AEE) na educação básica, o qual deve ser realizado no contra turno da escolarização e preferencialmente nas chamadas salas de recursos multifuncionais das escolas regulares, oferecendo um espaço mais específico para este atendimento no interior da escola.

Nesse contexto, em 2011, o Decreto o 6.571/08 é revogado pelo Decreto oo 7.611/2011 (BRASIL, 2011, n.p.), reafirmando no Art. $2^{\circ}$, que 
http://dx.doi.org/10.5902/1984686X35228

A educação especial deve garantir os serviços de apoio especializado voltado a eliminar as barreiras que possam obstruir o processo de escolarização de estudantes com deficiência, transtornos globais do desenvolvimento e altas habilidades ou superdotação.

Além disso, define o atendimento educacional especializado como o "[...] conjunto de atividades, recursos de acessibilidade e pedagógicos organizados institucional e continuamente", prestado de forma a

I - complementar à formação dos estudantes com deficiência, transtornos globais do desenvolvimento, como apoio permanente e limitado no tempo e na frequência dos estudantes às salas de recursos multifuncionais; ou II - suplementar à formação de estudantes com altas habilidades ou superdotação (BRASIL, 2008, n.p.)

Esses documentos foram de extrema importância para a organização política e pedagógica da educação especial no Brasil, culminando em transformações em todos os sistemas e redes de ensino.

A institucionalização do atendimento educacional especializado (AEE), de acordo com a Resolução n 4 de 2009, a qual institui as Diretrizes Operacionais para o Atendimento Educacional Especializado na Educação Básica, orientam que os sistemas de ensino devem disponibilizar a sala de recursos Multifuncionais (SRM) para a oferta do AEE. As Salas de Recursos Multifuncionais são ambientes dotados de equipamentos, mobiliários e materiais didáticos e pedagógicos (BRASIL, 2009). Deste modo, enfatiza-se que o (a) professor (a) que atua na SRM deverá atender somente alunos público alvo da educação especial ${ }^{2}$, no contra turno em que o aluno estiver frequentando o ensino comum.

\section{O Atendimento Educacional Especializado}

Conforme já exposto anteriormente, o atendimento educacional especializado (AEE), é uma ação advinda da política nacional de educação especial na perspectiva da inclusão escolar (BRASIL, 2008), e vem sendo foco de vários debates na área da educação especial, haja vista a importância desse espaço para que a inclusão de alunos público da educação especial, aconteça de fato.

As autoras Nunes e Borges (2017), realizaram uma revisão de literatura sobre essa temática e observaram que:

[...] a sala de recursos tem se tornado o lócus do atendimento educacional especializado na escola comum e essa tendência se agrava quando as ações na escola não são articuladas, colaborativas ou quando as salas de recursos multifuncionais se tornam o "espaço da Educação Especial" e não da escola. Os estudos nos evidenciam, também, sobre as concepções do conhecimento 
http://dx.doi.org/10.5902/1984686X35228

que em tese deveria ser trabalhado na sala de recursos multifuncionais. Percebemos que há posições diferentes em relação a essa questão (NUNES; BORGES, 2017, p. 310)

Além disso, as autoras destacam a importância de se tomar como foco de análise um conjunto de variáveis que podem ser utilizadas para estudar as salas recursos multifuncionais como um lócus do atendimento educacional especializado, conforme proposto nesse trabalho.

\section{Especificidades do AEE no Município de Cariacica-ES}

Neste item, tomamos como eixo de análise e discussão, a organização da Política de Educação Especial, no município de Cariacica-ES, a partir das ações desenvolvidas em uma escola de ensino fundamental da rede municipal.

$\mathrm{Na}$ escola pesquisada observou-se um quantitativo de 32 alunos público alvo da Educação Especial, nos turnos matutino, vespertino e noturno na Educação de Jovens e Adultos (EJA). Contabilizando $6 \%$ do alunado da escola. Neste quadro de alunos obtém as seguintes especificidades: Deficiência Intelectual, Transtornos Globais do Desenvolvimento e Deficiências Múltiplas.

Apesar de não ser público alvo do AEE, encontra-se um número significativo de alunos com Transtorno do Déficit de Atenção e Hiperatividade (TDAH) e alunos que ainda estão em investigação e que não possuem confirmação clínica de alguma deficiência ou transtorno, mas que são acompanhados diariamente e possuem um aprendizado extremamente comprometido. Sendo que estes, também recebem atenção da professora colaboradora em horários específicos, como uma proposta da escola de reforçar o aprendizado. Segue abaixo o gráfico 1 contendo a estatística dos alunos que frequentam o Atendimento Educacional Especializado na escola pesquisada:

Gráfico 1 - Quantitativo de Alunos do AEE

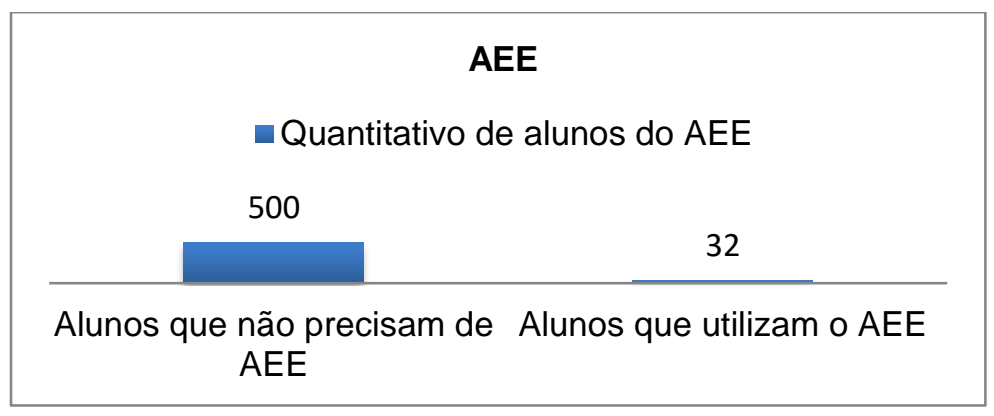

Fonte: Autores da pesquisa (2018) a partir de listagem geral de alunos matriculados fornecida pela Secretaria da Escola. 
Pode-se observar pelo quantitativo de alunos, que se trata de uma escola relativamente pequena e que por sua vez possui um número considerável de alunos com indicação para o atendimento educacional especializado, representando $6,4 \%$ do total de alunos matriculados na escola.

No entanto, apenas 22 alunos possuem laudos indicativos de deficiência e transtorno global do desenvolvimento e participam no contra turno na sala de Recurso Multifuncional. Os 10 alunos restantes, são alunos com indicativos de TDAH. Estes são atendidos pela professora colaboradora, no mesmo turno, em sala de aula, cada um em um horário específico.

No gráfico 2 apresenta-se as especificidades dos alunos matriculados na Escola Municipal em questão, atendidos na sala de recursos multifuncionais.

Gráfico 2 - Público Alvo da Educação Especial que frequenta o AEE da Escola

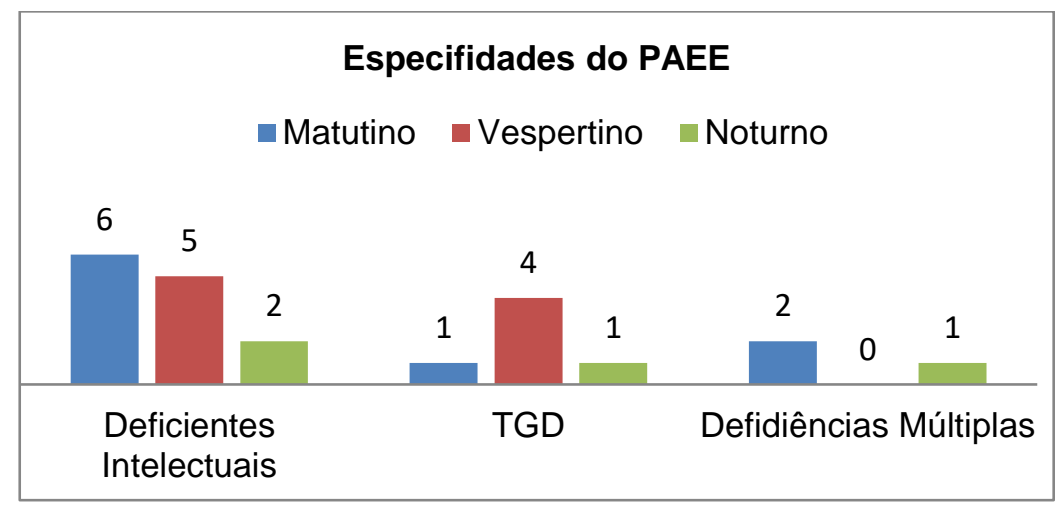

Fonte: Autores da pesquisa (2018) a partir de listagem geral de alunos matriculados fornecida pela Secretaria da Escola.

Para esmiuçar alguns predicados relacionados às especificidades presentes no gráfico acima utilizou-se alguns conceitos como a definição da Constituição Brasileira que pelo Decreto no 3.956/2001, promulgou a Convenção Interamericana para a Eliminação de Todas as Formas de Discriminação contra as Pessoas Portadoras de Deficiência, e afirma no seu artigo $1^{\circ}$ que, deficiência é [...] "uma restrição física, mental ou sensorial, de natureza permanente ou transitória, que limita a capacidade de exercer uma ou mais atividades essenciais da vida diária, causada ou agravada pelo ambiente econômico e social" (BRASIL, 2001, n.p.) reconhecendo assim que a deficiência é um conceito em evolução.

Nesse sentido, a deficiência mental/intelectual não se esgota na sua condição orgânica e/ou intelectual e nem pode ser definida por um único saber. Ela é uma interrogação e objeto de investigação de inúmeras áreas do conhecimento. Entende-se 
http://dx.doi.org/10.5902/1984686X35228

assim, que o professor do atendimento educacional especializado deve propor atividades que contribuam para a aprendizagem de conceitos, além de propor situações vivenciais que possibilitem esse aluno organizar o seu pensamento. Esse atendimento deve se fundamentar em situações-problema, que exijam que o aluno utilize seu raciocínio para a resolução de um determinado problema (GOMES; POULIN; FIGUEIREDO, 2010)

A segunda especificidade apontada no gráfico 2 trata-se dos alunos com TGD. Neste caso, a Política Nacional de Educação Especial na perspectiva da inclusão escolar (BRASIL, 2008a, p. 11), define os alunos da área dos transtornos globais do desenvolvimento, como aqueles que:

[...] apresentam alterações qualitativas das interações sociais recíprocas e na comunicação, um repertório de interesses e atividades restrito, estereotipado e repetitivo. Incluem-se nesse grupo estudantes com autismo, síndromes do espectro do autismo e psicose infantil.

Para os alunos com TGD é importante que haja recursos complementares e professores especializados que conheçam o aluno de forma aprofundada, estabelecendo um vínculo de confiança. Também é imprescindível a colaboração entre a família e a escola.

Alunos com Deficiências Múltiplas estão em menor número na realidade desta escola e também se encontram representados no gráfico 2. De acordo com as estratégias e orientações pedagógicas para a educação de crianças com necessidades educacionais especiais (BRASIL, 2002), O termo deficiência múltipla tem sido usado com frequência para caracterizar o conjunto de duas ou mais deficiências associadas de ordem física, sensorial e mental, emocional e comportamento social. No entanto,

[...] não é a somatória dessas alterações que caracteriza a múltipla deficiência, mas sim o desenvolvimento, as possibilidades funcionais, de comunicação de interação social e aprendizagem que determinam as necessidades educacionais especiais dessas pessoas (BRASIL, 2002, p. 11).

No atendimento a esse tipo de deficiência a professora da sala de recursos precisa criar estímulos onde o aluno possa se auto perceber e perceber o mundo exterior, deve-se buscar a sua verticalidade, o equilíbrio postural, a articulação e a harmonização de seus movimentos; o aperfeiçoamento das coordenações viso motora, motora global e fina; e o desenvolvimento da força muscular. Considera-se que a aprendizagem desses alunos é um dos grandes desafios da escola, pelo fato de constituírem um grupo com características específicas e peculiares, com necessidades únicas, chamando a atenção para dois 
aspectos considerados importantes: a comunicação e o posicionamento (BOSCO; MESQUITA; MAIA, 2010; NUNES; BORGES, 2017).

No próximo gráfico será exposto o quantitativo de alunos com Transtorno do Déficit de Atenção e Hiperatividade. Esses alunos não são reconhecidos como público alvo da educação especial, todavia requerem um olhar diferenciado no processo de ensino aprendizagem. O gráfico 3 representa a quantidade de alunos com TDHA, matriculados na escola em questão.

Gráfico 3 - Alunos com TDAH

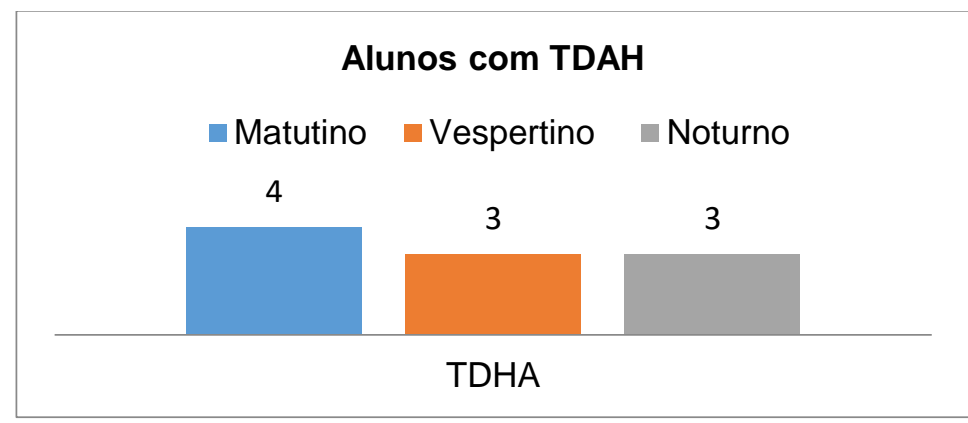

Fonte: Autores da pesquisa (2018) a partir de listagem geral de alunos matriculados fornecida pela Secretaria da Escola.

O transtorno do déficit de atenção e hiperatividade, também conhecido como TDAH, é um transtorno que dificulta o foco, a atenção e ocasiona a impulsividade; é mais comum em crianças e esse tipo de transtorno pode ser observado no inicio da fase escolar, onde a criança não consegue realizar por completo suas atividades (GONÇALVES, 2010)

Além dos (as) alunos considerados (as) público alvo da educação especial (PAEE) e os (as) alunos (as) com TDHA encontra-se também um grupo de alunos com características equivalentes as dos PAEE, que estão em processo de investigação pedagógica e clínica, conforme mostra o gráfico 4.

Gráfico 4 - Alunos em Processo de Investigação Pedagógica

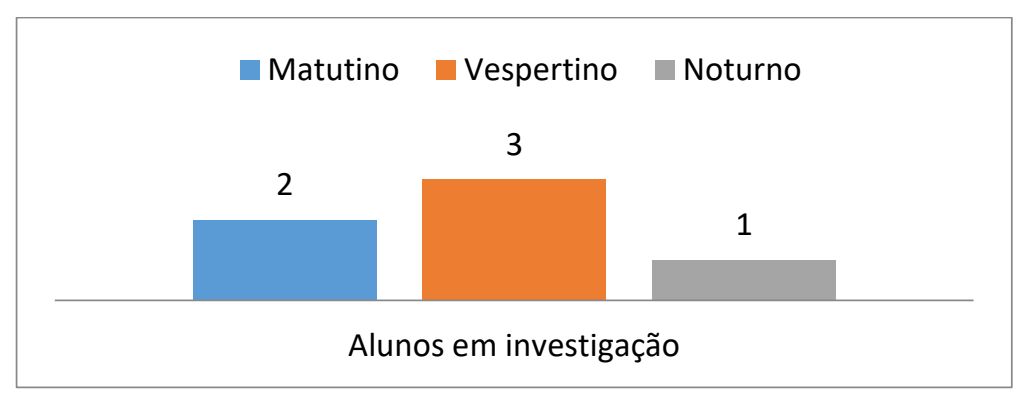

Fonte: Secretaria da escola - Fonte: Autores da pesquisa (2018) a partir de listagem geral de alunos matriculados fornecida pela Secretaria da Escola. 
As normas advindas dos documentos nacionais para o atendimento aos alunos público alvo da educação especial, reverberam no município de Cariacica-ES, de modo que o público alvo atendido é o mesmo que é definido na Política Nacional de Educação Especial e no decreto 7611/2011. No entanto, considerando cada criança um ser único, e considerando as dificuldades da escola em trabalhar com a diversidade humana, outros sujeitos vão se tornando elegíveis às salas de recursos multifuncionais, daí o aparecimento desse grupo, em processo de investigação.

Dentre as possibilidades de organização do Atendimento Educacional Especializado (AEE), previsto na legislação nacional, conceitua-se no município de Cariacica, o (a) Professor (a) Colaborador (a) de Ações Inclusivas (PCAI), que visa acompanhar na própria sala de aula regular, em horários previamente acordados, o (a) aluno(a) Público Alvo da Educação Especial (PAEE) e a Sala de Recursos Multifuncionais (SRM), que oferece dentro da escola, um espaço específico, no contra turno do aluno, um professor especializado, recursos e materiais pedagógicos diversos e adaptados para este fim.

Fazem parte das atribuições do (a) PCAI articular junto ao pedagogo (a), professor (a) regente e gestor (a) as ações pertinentes à área da Educação Especial/Inclusiva, participando das reuniões, planejamentos, levantamento pedagógico, processos avaliativos, conselho de classe e formações na Unidade de ensino; Responsabilizar-se pela realização de adaptação e adequação de material pedagógico e currículo para o (a) aluno (a) público-alvo; e reitera-se que o PCAI deve atuar juntamente com os professores regentes intervindo diretamente com o (a) aluno (a) Público Alvo da Educação Especial (PAEE) na sala de aula comum a fim de que este acesse os conteúdos curriculares da turma que estiver inserido (CARIACICA, 2018)A seguir, apresenta-se o gráfico 5, onde é exposto o número de alunos atendidos pela professora colaboradora.

Gráfico 5 - Número de alunos atendidos pela PCAI

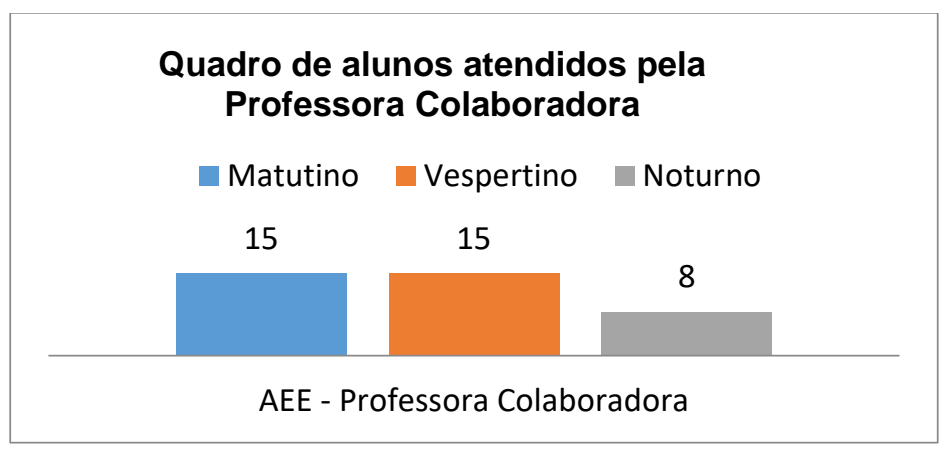

Fonte: Autores da pesquisa (2018) a partir de lista de alunos atendidos pela PCAI fornecida. 
Essas representações gráficas que demonstram a relação numérica dos alunos que recebem atendimento educacional especializado servem para obter um quantitativo específico, onde a partir desses resultados a escola se organiza para atender os alunos de forma qualificada.

Desta maneira sabe-se que todos os alunos estimados nos gráficos 1,2 , 3 e 4 recebem nos seus respectivos turnos o atendimento com a Professora Colaboradora referente. Este atendimento visa oferecer um suporte para o aluno público alvo da educação especial. Portanto, em horários determinados, cada aluno passa um período do dia com essa profissional, que adapta suas atividades de sala para que o mesmo possa realiza-la efetivamente. $\mathrm{Na}$ ausência da professora colaboradora, a professora regente realiza as adaptações normalmente para o aluno PAEE.

$O$ atendimento na SRM acontece no contra turno para aqueles alunos que possuem laudo que comprove a deficiência e a família aceita este serviço. Portanto no gráfico 6 , mostra os alunos público alvo que participam desse atendimento.

Gráfico 6 - Alunos atendidos na Sala de Recursos Multifuncional

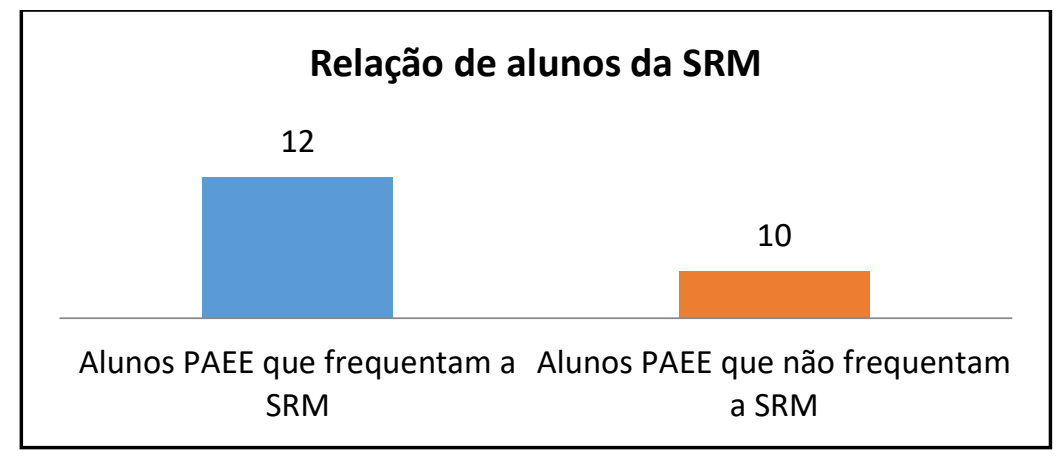

Fonte: Autoria própria (2018) baseada em listagem de alunos fornecida pela Secretaria da Escola.

Apesar de o aluno ter garantido seu direito a Sala de Recurso Multifuncional, no contra turno escolar, para complementar ou suplementar seus estudos, nem todos os alunos usufruem desse atendimento por motivos diversos. Entre os motivos pesquisados encontrou-se: a família não pode trazer; a família não quer trazer; a família prefere outro atendimento especializado, como o que é feito nas APAES. Portanto, não são todos os alunos público alvo que frequentam a Sala de Recurso Multifuncional no contra turno, contabilizando um total de apenas 12 atendidos. 


\section{Reflexões acerca do AEE na visão dos professores desta Unidade de Ensino}

O processo de ensino aprendizagem realizado no ambiente escolar que seja de caráter significativo e realmente eficaz para os alunos é um grande desafio para todos os professores. E ao se tratar da educação especial não é diferente, pois apesar de notória a evolução do sistema educacional voltado para este público, ainda não se alcançou o patamar de inclusão almejado.

Foi realizado um questionário com perguntas que abrangem o AEE desta EMEF em questão, para compreender melhor os anseios do corpo docente e os desafios do trabalho pedagógico. Responderam ao questionário 20 professores (as), que compõem o quadro de regentes no matutino (8), vespertino (8) e noturno- EJA (4).

A primeira questão foi sobre a formação dos profissionais da escola, voltada para educação especial. Questionando: Você já realizou algum curso teórico ou prático na área da educação especial?

Gráfico 7 - Professores que Realizaram Cursos na Área da Educação Especial

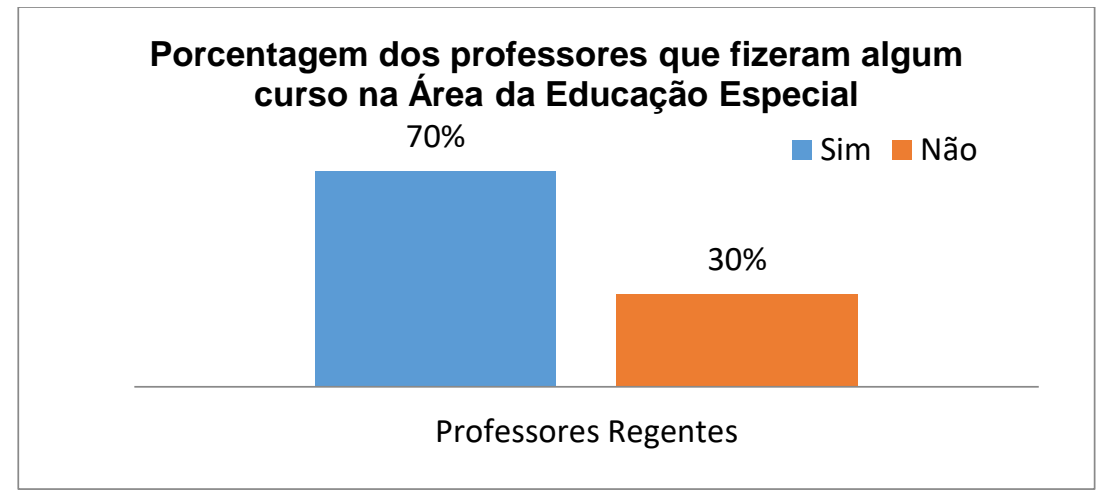

Fonte: Autoria própria (2018) baseado no questionário feito aos professores desta EU.

Pode-se observar que dos 20 professores que responderam ao questionário, 14 já realizaram algum curso na área da educação especial, e 6 professores não realizaram. Mostrando que ainda existe um número significativo de professores que não realizou nenhum tipo de curso voltado para a Educação Especial, no entanto a maioria o fez, pontuando a relevância da formação continuada nas áreas diversas do conhecimento docente.

Embora a maioria dos professores reconheçam a necessidade de formação nessa área do conhecimento é percebido que os $30 \%$ dos professores ainda não chegaram a essa conclusão, isso implica um grande desafio ainda para a reflexão sobre os processos educativos do aluno público alvo da educação especial. Destarte, pesquisas apontam que 
a formação dos professores para a Educação Especial/inclusão escolar, não pode ser considerada isoladamente, é preciso considera-la como parte integrante dos profissionais da educação em geral e submetê-la às mesmas discussões que vêm fazendo no âmbito nacional, estadual ou regional (CARTOLANO, 1998).

A pergunta 02 teve a intenção de desvelar a concepção dos professores sobre o AEE, assim foi solicitado que respondessem: qual o objetivo do Atendimento Educacional Especializado e quem são os alunos Público Alvo da educação especial.

Gráfico 8 - Concepção dos Professores sobre o Objetivo e o Público Alvo do AEE

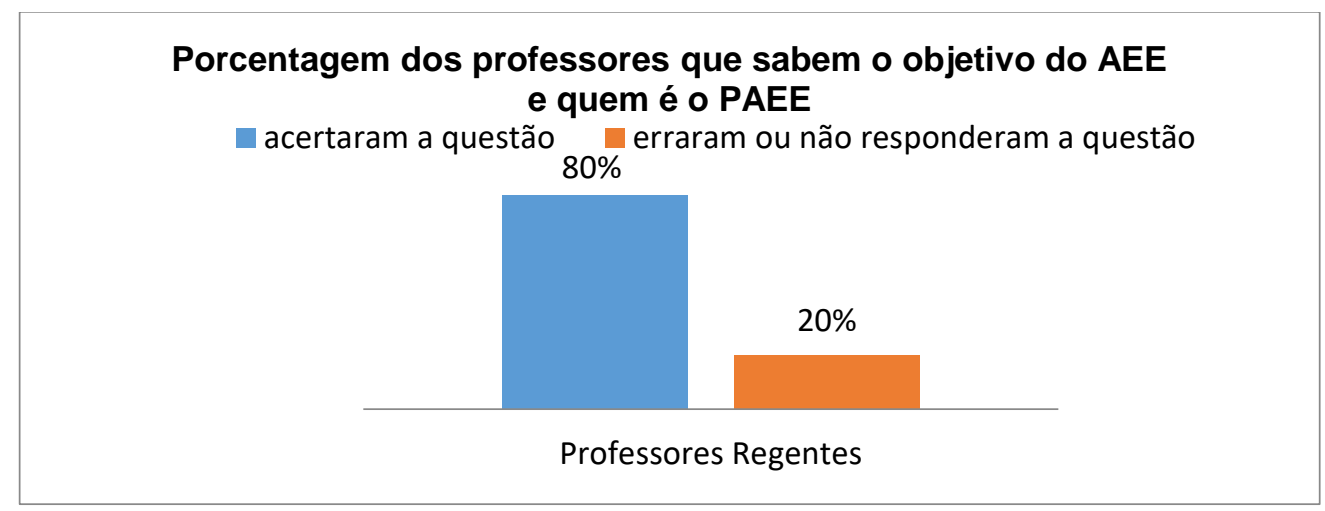

Fonte: Autoria própria (2018) baseado no questionário feito aos professores desta EU.

A grande maioria dos professores que responderam ao questionário, demonstraram saber que o Atendimento Educacional Especializado está para complementar e/ou suplementar a formação dos alunos PAEE (com deficiência, TGD e Superdotação), de acordo com os documentos que orientam e regem a organização do Atendimento Educacional Especializado.

Ressalta-se que o Atendimento Educacional Especializado foi instituído pela Resolução no 04/2009 (BRASIL, 2009, p. 1) - Diretrizes Operacionais da Educação Especial na Educação Básica, definindo no Art. $2^{\circ}$ que:

O AEE tem como função complementar ou suplementar a formação do aluno por meio da disponibilização de serviços, recursos de acessibilidade e estratégias que eliminem as barreiras para a sua plena participação na sociedade e desenvolvimento de sua aprendizagem.

Daí, percebe-se a relevância desse atendimento como complementar ou suplementar no processo de ensino e aprendizagem do aluno público alvo da educação especial, o que torna também fundamental que o professor da sala de aula tenha conhecimento do objetivo desse atendimento para que o mesmo seja articulado com o conteúdo que está sendo 
ensinado na sala de aula. Só assim, poderá efetivamente eliminar as barreiras para a plena participação do aluno PAEE nos processos de ensino e aprendizagem.

A pergunta de número 03 solicitou aos professores que respondessem sobre o papel do professor colaborador nas ações Inclusivas e o papel do professor da sala de recursos multifuncional nos processos de ensino e aprendizagem do aluno PAEE.

Gráfico 9 - Papel do Professor Colaborador e da Sala de Recursos

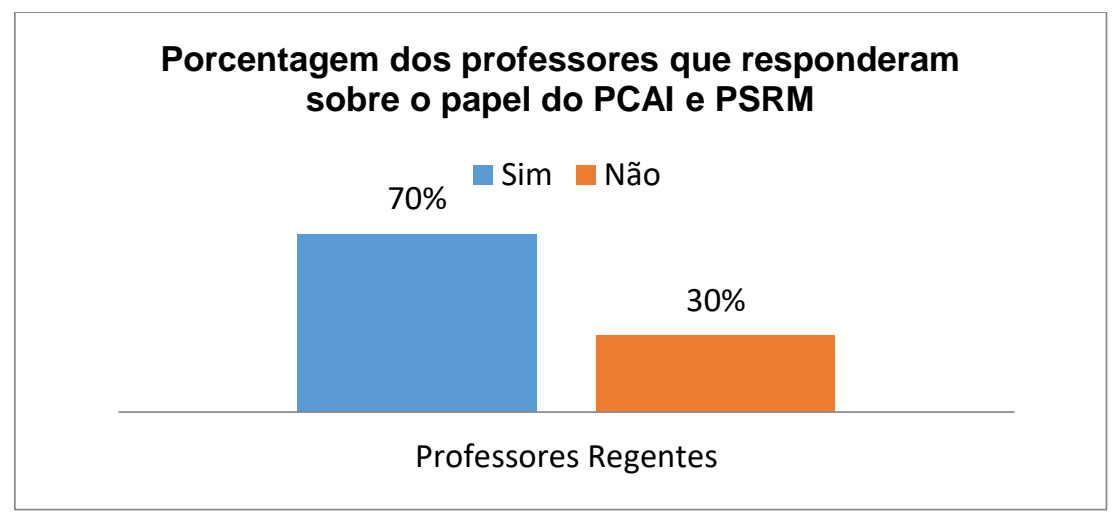

Fonte: Autoria própria (2018) baseado no questionário feito aos professores desta EU.

Observa-se que é o mesmo grupo de professores que não tem formação na área da educação especial, ou que o conhecimento dessa área não perpassou pela sua formação inicial. Se os professores não reconhecem o papel do professor da sala de recursos ou do professor colaborador, existem muitas lacunas no trabalho e/ou barreiras no processo de ensino e aprendizagem dos alunos PAEE.

Vilaronga e Mendes (2014), em pesquisa realizada na cidade de São Carlos - SP, sobre uma proposta de trabalho colaborativo e co-ensino para apoio à inclusão escolar, Concluem que a literatura científica relacionada ao co-ensino e trabalho colaborativo, apesar de promissora, "evidencia a necessidade de mais estudos sobre a colaboração entre o professor regular e o de educação especial nas escolas, bem como a preparação efetiva dos profissionais que atuam em Educação Especial” (p. 149).

$\mathrm{Na}$ pergunta 04 questionou-se como o professor se articula com o professor colaborador para que ambos possam atender adequadamente as necessidades do aluno que têm em comum. Doze professores responderam que se articulam por meio dos planejamentos em conjunto onde conversam sobre as adaptações que serão feitas. Quatro (4) professores disseram não ter articulação com o professor colaborador, pois os planejamentos não são juntos. Dois (2) professores não responderam e dois (2) professores 
http://dx.doi.org/10.5902/1984686X35228

disseram que realizam suas atividades normalmente e o PCAI adapta a atividade para o AEE.

Nesse sentido, o trabalho de Vilaronga e Mendes (2014, p. 148), no que tange aos esses papéis do professor da sala de aula e do professor colaborador, ressaltam que

[...] na colaboração o professor especialista e o professor da sala comum devem ter um projeto mínimo de atividade com os alunos com deficiência, em concordância com o que está sendo trabalhado no currículo da sala. O professor da sala comum deve obter informações com o professor consultor sobre os estudantes, para quem os planos individualizados foram construídos, e discutir com ele sobre as adaptações individuais para esses alunos.

Pactuamos com as autoras, uma vez que entendemos que o trabalho colaborativo entre o professor da sala de aula e o professor colaborador, deve ter uma sintonia em todos os aspectos, seja na obtenção de informações sobre o aluno atendido por ambos professores, sejam na proposta de um projeto educativo direcionado para o aluno.

$\mathrm{Na}$ questão 5 foram listadas algumas especificidades para que os professores marcassem aquelas que mais tem conhecimento teórico prático. Seis (6) responderam Autismo, Um (1) Asperger, três (3) Deficiência Intelectual, um (1) Deficiência Auditiva, um (1) deficiência física, quatro (4) Deficiências Múltiplas e dois (2) Deficiência visual.

Nessa questão, observa-se que a mídia tem uma grande responsabilidade pela disseminação desse conhecimento, já que o autismo, nos últimos anos tem sido visibilizado na sociedade, sobretudo a partir de 2012, com a aprovação da Lei 12.764/2012 (BRASIL, 2012), o qual instituiu a Política Nacional de Proteção dos Direitos da Pessoa com Transtorno do Espectro Autista, estabelecendo diretrizes, tanto na área educacional quanto social dos direitos da criança com autismo.

No entanto, há que se destacar que o campo do conhecimento sobre o "autismo está na encruzilhada de várias disciplinas" (VASQUEZ, 2008, p. 49). A diversidade de abordagens reflete a complexidade da temática, que não pode ser capturada por uma única perspectiva. Ainda segundo Vasques (2008, p. 49),

A existência de múltiplas interpretações impede consensos em relação aos sujeitos e as possibilidades subjetivas, sociais, clínicas, educacionais, bem como sobre as estratégias ou recursos que podem favorecer (ou não) o desenvolvimento global e a constituição subjetiva. Tais dissonâncias, se compreendidas a partir de uma processualidade histórico-conceitual, não constituem um limite teórico-prático. Ao contrário, a pluralidade de lentes/perspectivas pode representar um primeiro passo no sentido de adimitir soluções diferentes para as questões suscitadas no atendimento destas crianças e adolescentes. 
A autora nos aponta pistas para refletir que não basta ter o conhecimento geral sobre a deficiência, tendo em vista que a multiplicidade de informações que a própria mídia disponibiliza sobre o autismo, não se reverbera em soluções para as questões suscitadas na prática educacional com a criança ou adolescente autista.

Já a questão 6 enfatizou sobre as dificuldades em realizar seu trabalho pedagógico, de acordo com as especificidades. E das respostas, quatro (4) dos professores responderam, Deficiência Intelectual, dois (2) responderam deficiência física, oito (8) responderam TGD's, quatro (4) responderam Deficiência Visual e dois (2) responderam deficiências múltiplas.

Mittler (2008), Santos e Martins (2015) dentre outros autores, apontam que um dos grandes desafios que se apresentam para a inclusão dos alunos com deficiência intelectual em salas comuns parte da própria escola e dos seus educadores que, muitas vezes, têm uma visão distorcida dessas crianças, percebendo-as como diferentes e entendendo que a tarefa de educá-las requer um conhecimento e uma experiência especial.

Entendemos que a forma de conceber a deficiência prejudicou o início do processo de inclusão do aluno com deficiência intelectual nas escolas comuns e fortaleceu mitos sobre a sua aprendizagem, construídos socialmente a partir de atitudes preconceituosas e segregacionistas de educadores, pois o temor pela diferença permeou em grande parte a discriminação que afeta, muitas vezes, as escolas. Outro fator que contribuir para essa forma dos professores conceber a deficiência intelectual, foi o fato de grande número desses alunos com deficiência intelectual serem oriundos das instituições especializadas.

E na última pergunta buscou desvelar o maior desafio em relação ao trabalho com alunos PAEE nesta EMEF. Das respostas, Oito (8) professores responderam que o PCAI permanece por pouco tempo no atendimento na sala regular e algumas vezes tira a criança de sala. Quatro (4) responderam sobre o espaço físico da escola, por ser uma escola pequena, com poucos recursos estruturais e adaptações arquitetônicas. Um (1) relatou sobre a falta de laboratório de informática e um (1) diz ter números excessivos de alunos por turma. Um professor disse ainda que não possui dificuldades. Três (3) disseram que 0 seu maior desafio é planejar seu trabalho junto com o PCAl, uma vez que seus planejamentos são separados.

O que mais nos chama a atenção nas respostas dos entrevistados é a queixa que imprimem sobre o fato do PCAI permanecer pouco tempo na sala de aula. Entendemos que 
existe uma necessidade por parte dos entrevistados em obter esse profissional um pouco mais em sala no processo colaborativo.

Todavia, a crença nas possibilidades da criança, poderia ser o impulso para que ocorresse o ensino, aprendizado e o fortalecimento do processo de inclusão. Portanto, a inclusão dos alunos PAEE na escola regular só se realiza, de fato, "se houver respeito à diferença, evidenciado pela interação com as possibilidades e limitações desse alunado, por meio de práticas pedagógicas que estimulem o seu desenvolvimento" (PRIETO; SOUZA, 2006, p. 188).

Diante da realidade investigada, verificamos que muitas das dificuldades situadas pelos docentes e observadas no cotidiano escolar têm origem nas lacunas da própria formação de professores.

\section{Considerações finais}

Nesta pesquisa podemos investigar os caminhos que a educação especial trilhou para que nos dias atuais e no município de Cariacica pudesse realizar o trabalho que é feito com os alunos Público Alvo da Educação Especial. Observou-se que na EMEF em questão o trabalho do AEE está desenvolvido de acordo com as normas legais municipais e federais. Ao ponto que se mantém legítima e organizada.

Nesta Unidade de Ensino possui o Atendimento Educacional Especializado sob a responsabilidade da escola, em termos gerais, da Professora Colaboradora de Ações Inclusivas (PCAI) e Professora da Sala de Recursos Multifuncionais (PSRM) de maneira específica. O processo de escolarização e aprendizagem se organiza para atender de maneira relevante, ao atendimento educacional especializado, $6 \%$ do alunado, que tem suas especificidades voltadas para a deficiência mental/intelectual, deficiências Múltiplas e Transtornos Globais do Desenvolvimento. Além de contar um número significativo de alunos com Transtorno do Déficit de Atenção e Hiperatividade (TDAH) e alunos que estão em investigação pedagógica e clínica, por possuírem características de aprendizagem, pessoais e sociais, que requerem atenção específica.

Todos os alunos caracterizados como público alvo da educação especial recebem atendimento especializado em seus respectivos turnos com a professora colaboradora, que é responsável, em conjunto com a professora regente, adequar, adaptar e mediar as atividades feitas em sala de aula. Este atendimento na sala regular é definido previamente 
http://dx.doi.org/10.5902/1984686X35228

por horário estipulado pela pedagogia da escola, que leva em consideração a necessidade do aluno e as demandas da escola para esta professora colaboradora.

Os alunos Público Alvo da Educação Especial, também contam com o atendimento, no contra turno, na sala de recurso multifuncional com a respectiva professora desta sala, que visa complementar ou suplementar os estudos do turno regular. O trabalho da professora da sala de recursos é planejado junto aos pedagogos e professores regentes do turno que o aluno estuda. A aceitação do direito de frequentar a sala de recurso é facultativa ao aluno e seus familiares. E este aluno só poderá ser atendido se não estiver frequentando nenhuma outra instituição de educação especializada como APAE's e Pestalozzi's.

Após compreender o trabalho desenvolvido, buscou-se indagar os professores através de questionário suas ressalvas sobre o AEE da Unidade de Ensino. As questões estabelecem uma linha de investigação para permear as características dos professores envolvidos. Todavia através do questionário, descobriu-se que seis (6), ou seja, $30 \%$ dos professores nunca realizaram curso de formação sobre a educação especial. Um indicativo interessante, que pode indicar uma lacuna presente na formação teórica desta porcentagem de professores.

Em seguida as questões se voltam para o conhecimento ou não dos professores a respeito da finalidade do AEE, PCAI e PSRM. Mais um dado relevante recolhido desta pesquisa. $20 \%$ dos professores da escola não sabem o objetivo do AEE e $30 \%$ não sabem qual o papel do PCAI e PSRM. Estes esclarecimentos sobre as funções dos profissionais que estão a frente do AEE deve ser algo intrínseco da escola e todo o corpo docente precisa reconhecer seu papel, pois somente assim farão um trabalho em conjunto que levará em consideração a qualidade do ensino do aluno PAEE. Esta falta de conhecimento sobre as intervenções dos professores do AEE reflete na próxima pergunta do questionário que indaga sobre a articulação do professor regente e o professor colaborador. E um número 4 respostas indicam que não fazem articulação com o professor colaborador possivelmente diminuindo a qualidade do processo.

Quando as perguntas se voltam para o conhecimento teórico sobre as especificidades dos alunos: Seis (6) responderam compreender bem o Transtorno do Autismo, três (3) Deficiência Intelectual, e quatro (4) Deficiências Múltiplas e os outros responderam isoladamente a outras deficiências ou síndromes. Quanto as suas dificuldades perante seus próprios conhecimentos e a sua atuação com o aluno frente a esta dificuldade, a maioria possui maior dificuldade em trabalhar com alunos com TGD. 
A última pergunta indaga o maior desafio encontrado na escola para atuar nos processos da Educação Especial. A maioria revela que possui dificuldades em planejar junto ao PCAI para ambos formarem as adequações necessárias para o aluno, além de reclamarem sobre o pouco tempo que o PCAI permanece em sala com seus alunos, devido a demanda a ser atendida na escola.

É possível notar que algumas adequações deverão ser feitas para qualificar o processo de ensino aprendizagem desta UE: incentivo e oportunidades de formação continuada, oferecimento de palestras esclarecedoras para o corpo docente, reuniões pedagógicas que enfatizem o papel dos PCAI e PSRM, além de ajustamentos no horário de planejamento, e até mesmo a solicitação de mais um funcionário PCAI para melhorar o AEE.

Portanto o estudo acerca desta escola foi proveitoso e puderam-se compreender melhor os anseios dos professores perante seu trabalho e investigar as características dos alunos PAEE. De posse desses dados sugere-se um estudo coletivo com a equipe pedagógica da escola para que ambos articulem um posicionamento perante suas dificuldades e barreiras e assim possam buscar alternativas que beneficiem o trabalho desenvolvido.

\section{Referências}

BAPTISTA, Claudio Roberto; JESUS, Denise Meyrelles. Avanços em políticas de inclusão - O contexto da educação especial no Brasil e em outros Países. Editora Mediação. Porto Alegre, 2011.

BOSCO, Ismênia Carolina Mota Gomes; MESQUITA, Sandra Regina Stanziani Higino; MAIA, Shirley Rodrigues. Surdocegueira e Deficiência Múltipla. Fortaleza, Universidade Federal do Ceará, v. 5. Coleção: A Educação Especial na Perspectiva da Inclusão Escolar. 2010.

BRASIL. Constituição da República Federativa do Brasil. Brasília, DF: Senado Federal. Artigo 205, 1988.

BRASIL. Lei de Diretrizes e Bases da Educação Nacional. Lei número 9394, 20 de dezembro de 1996.

BRASIL. Estratégias e orientações pedagógicas para a educação de crianças com necessidades educacionais especiais. Brasília: Ministério da Educação, 2002. Disponível em: http://portal.mec.gov.br/seesp/arquivos/pdf/livro10. Acesso em: 06 mai. 2018.

BRASIL. Secretaria de Educação Especial. Política Nacional de Educação Especial na Perspectiva da Educação Inclusiva. Brasília, DF, jan. 2008a. 
BRASIL. Decreto n. 6.571/2008. Dispõe sobre o Atendimento Educacional Especializado, regulamenta o parágrafo único do artigo 60 da lei n. 9.394, de 20 de dezembro de 1996, e acrescenta dispositivo ao decreto n. 6.253, de 13 de novembro de 2007. Diário Oficial da União, Brasília, DF, 18 set. 2008b.

BRASIL. Conselho Nacional de Educação. Câmara de Educação Básica. Resolução n. 4, de 2 de outubro de 2009. Institui Diretrizes Operacionais para o Atendimento Educacional Especializado na Educação Básica, modalidade Educação Especial. Brasília, DF, 2009.

BRASIL. Decreto no 7.611, de 17 de novembro de 2011. Dispõe sobre a educação especial, o atendimento educacional especializado e dá outras providências. Diário Oficial da União, Brasília, DF, 18 nov. 2011.

BRASIL. Lei no 12.764 de 27 de dezembro de 2012. Política Nacional de Proteção dos Direitos da Pessoa com Transtornos do Espectro Autista. Presidência da República, Casa Civil.

CARIACICA, Prefeitura Municipal de. Secretaria Municipal de Educação- Coordenação de Diversidade e Inclusão Educaciona I- Orientações sobre a Educação Especial no Município de Cariacica. Cariacica, 2018.

CARIACICA. Resolução 007, de 27 de dezembro de 2011. Fixa normas para a Educação Básica no Sistema Municipal de Ensino do Município de Cariacica. Disponível em: http://www.legislacaocompilada.com.br/cariacica/consulta.aspx. Acesso em: 14 nov. 2017.

CARTOLANO, Maria Teresa Penteado. Formação do educador no curso de pedagogia: A educação especial. Cadernos CEDES vol.19 n.46 Campinas. 1998.

CASTILHO, Ana Flávia de Andrade Nogueira; STEFANO, Lara Bianca. Deficiência Intelectual e o direito fundamental à Educação no Brasil, Ano 3 (2017), ํo2, 71-91. RJLB. Disponível em:

http://www.cidp.pt/publicacoes/revistas/rjlb/2017/2/2017_02_0071_0091.pdf. Acesso em: 14 nov. 2017.

COLL, César; MARCHESI, Álvaro; PALACIOS, Jesús. Desenvolvimento Psicológico e Educação- Transtornos de desenvolvimento e necessidades educativas especiais. Volume 3. Artmed, Porto Alegre, 2004.

DECLARAÇÃo DE SALAMANCA. Adaptada pela Conferência Mundial sobre Necessidades Educativas Especiais: Acesso e Qualidade. UNESCO, 1994.

FERREIRA, Eliza Bartolozzi; OLIVEIRA, Dalila Andrade; VIEIRA, Lívia Fraga. O Trabalho Docente na Educação Básica no Espírito Santo. Fino Traço. Belo Horizonte, 2012.

GOMES, Adriana L. Limaverde (et al). Formação Continuada a Distância de Professores para o Atendimento Educacional Especializado: Deficiência mental. SEESP / SEED / MEC Brasília/DF - 2007. 
http://dx.doi.org/10.5902/1984686X35228

GIL, Antonio Carlos. Como elaborar projetos de pesquisa. 4. ed. São Paulo: Atlas, 2002.

GOMES, Adriana Leite Lima Verde; POULIN, Jean-Robert; FIGUEIREDO, Rita Vieira de. O Atendimento Educacional Especializado para Alunos com Deficiência Intelectual. Fortaleza, Universidade Federal do Ceará, v. 2. Coleção: A Educação Especial na Perspectiva da Inclusão Escolar. 2010.

GONÇALVES, Samara Cunha. O TDAH (Transtorno de Déficit de Atenção e Hiperatividade) no contexto escolar: Uma Visão Psicopedagógica. Universidade Candido Mendes, Curso de Pós-Graduação em Psicopedagogia. Niterói. 2010.

VILARONGA, Carla Ariela Rios; MENDES, Eniceia Gonçalves; Ensino colaborativo para o apoio à inclusão escolar: práticas colaborativas entre os professores. Revista Brasileira de Estudos Pedagógicos (online), Brasília, v. 95, n. 239, p. 139-151, jan./abr. 2014.

MITTLER, Peter. Educação Inclusiva. Contextos sociais. Artmed. São Paulo, 2008.

NUNES, Isabel Matos; BORGES, Carline Santos; Atendimento Educacional Especializado: diversos olhares. In, OLIVEIRA, I. M. de; RODRIGUES, David e JESUS, D. M. (Orgs.) Formação de Professores, Práticas pedagógicas e inclusão escolar: Perspectivas luso-brasileiras. Vitória. Edufes, 2017.

OLIVEIRA, Ivone Martins de; RODRIGUES, David; JESUS, Denise Meyrelles de. Formação de professores, Práticas Pedagógicas e Inclusão Escolar. Edufes. Vitória, 2017.

PRIETO, Rosangela Gavioli; SOUSA, Sandra Zákia Lian. Educação Especial no município de São Paulo: acompanhamento da trajetória escolar de alunos no ensino regular. Rev.

Bras. Ed. Esp., Marília, Mai.- Ago. 2006, v.12, n.2, p.187-202

SANTOS, Teresa Cristina Coelho dos; MARTINS, Lúcia de Araújo. Práticas de ProfessoresFrente ao Aluno com Deficiência Intelectual em Classe Regular. Rev. Bras.

Ed. Esp., Marília, v. 21, n. 3, p. 395-408, Jul.-Set., 2015.

VASQUES, Carla Karnoppi. Alice na biblioteca mágica: uma leitura sobre o diagnóstico e a escolarização de crianças com autismo e psicose infantil. Tese de doutorado. Porto Alegre: PPGEDU/UFRGS, 2008.

VERGARA, Sylvia Constant. Projetos e relatórios de pesquisa em Administração. 2a ed. São Paulo: Atlas 1988.

\section{Notas}

\footnotetext{
${ }^{1}$ Escolhemos utilizar essa nomenclatura neste artigo, tendo em vista as definições do documento da Política Nacional de Educação Especial na perspectiva da Educação Inclusiva (BRASIL, 2008).

2 De acordo com a Política Nacional de Educação Especial (BRASIL, 2008), esse público são os alunos com deficiência, transtornos globais de desenvolvimento e altas habilidades/superdotação.
} 
http://dx.doi.org/10.5902/1984686X35228

\section{Correspondência}

Christine Avelar Borges Faria - Rua Sorocaba, no 15, quadra 37, Marcílio de Noronha, Viana, Espírito Santo, Brasil.

CEP: 29135-372

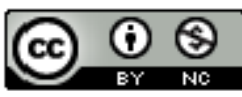

This work is licensed under a Creative Commons Attribution-NonCommercial 4.0 International (CC BY-NC 4.0) 